\title{
Present treatment options in congestive heart failure
}

\author{
W J Remme
}

STICARES,

Cardiovascular

Research Foundation,

PO Box 52006, 3007 LA

Rotterdam,

Netherlands

W J Remme

Correspondence to:

Professor Remme.
Current treatment of congestive heart failure has a dual approach: it aims to relieve symptoms, such as breathlessness and oedema, and to improve wellbeing. The effects are measurable and treatment can be adapted depending on whether it improves patients' symptoms. Recently, and mainly as the result of a decade of large trials in heart failure, a different approach to treatment has emerged. ${ }^{1}$ The focus of treatment is now on preventing worsening of heart failure and improving survival.

This review explores achievements in the treatment of heart failure and discusses ongoing strategies to improve symptoms and to prevent progression.

\section{Clinical experience in heart failure}

Historically, most forms of heart failure treatment were developed to improve symptoms rather than prevent progression. However, the therapeutic focus is gradually shifting towards the prevention of progression. Various mechanisms are known to be involved in this process, and an understanding of their importance and the development of agents to affect these mechanisms may allow an improvement in prognosis.

An important factor that contributes to the progression of heart failure and which could be a target of treatment is cardiac remodelling; in this process, the heart hypertrophies in various places, eventually inappropriately, while also dilating. Other factors involved in the progression of heart failure include neurohormonal and peptide activation, cytokine activation, apoptosis, and free radical production. $\beta$ Receptor downregulation and uncoupling, abnormalities in intracellular signalling pathways, and, in particular, abnormalities of sarcoplasmic reticulum function that lead to a loss of calcium homeostasis are also involved.

These factors are potential targets of treat-

ment aimed at slowing down or, possibly, reverting the processes that lead to progressive heart failure. Novel forms of heart failure treatment, such as angiotensin converting enzyme (ACE) inhibition, angiotensin II receptor antagonism, $\beta$ blockade, and carvedilol, influence some of these factors, while other treatments are mainly concerned with improvement of symptoms.

\section{Drug treatment}

POSITIVE INOTROPIC AGENTS

It is generally agreed that positive inotropic agents improve haemodyamic function and, particularly in patients with severe heart failure, they may provide temporary symptomatic improvement. Digitalis is the only positive inotropic agent that has been approved in the Western world for long term use in chronic heart failure. However, positive inotropes delivered intravenously such as dobutamine or the cAMP dependent phosphodiesterase inhibitors enoximone and milrinone have a temporary role in acute heart failure or as a bridge to further, more definite treatment in patients with severe, end stage heart failure. It is generally agreed that oral cAMP dependent agents should not be given long term, as their efficacy in improving symptoms has not been proved, and because they are associated with severe adverse events including increased mortality. ${ }^{2}$

Calcium sensitisers may offer another approach in heart failure. These novel positive inotropes do not act by increasing cAMP or intracellular calcium but rather by sensitising the contractile apparatus to intracellular calcium. ${ }^{3}$ Further long term controlled studies are needed to prove whether these agents are more efficacious and have a better side effect profile than currently available positive inotropes.

\section{Glossary}

AIRE: Acute infarction ramipril efficacy

ATLAS: Assessment of treatment with lisinopril and survival

CONSENSUS: Cooperative north Scandinavian enalapril survival study

DIG: Digitalis Investigation Group

RALES: Rationale for the randomized aldactone evaluation study

SOLVD: Studies of left ventricular dysfunction

V-HeFT: Ventricular heart failure trial

\section{Digitalis}

Digitalis indirectly increases intracellular calcium concentrations principally by inhibiting sodium/potassium dependent ATPase. This results in an increase in contractile force in the heart and may lead to vasoconstriction. Digitalis has important secondary effects; it sensitises arterial baroreceptors and cardiac volume receptors, particularly vagal afferents. Consequently, it increases and improves parasympathetic activity and reduces sympathetic outflow. In patients with heart failure this results in a significant reduction of cardiac muscle sympathetic activity. 


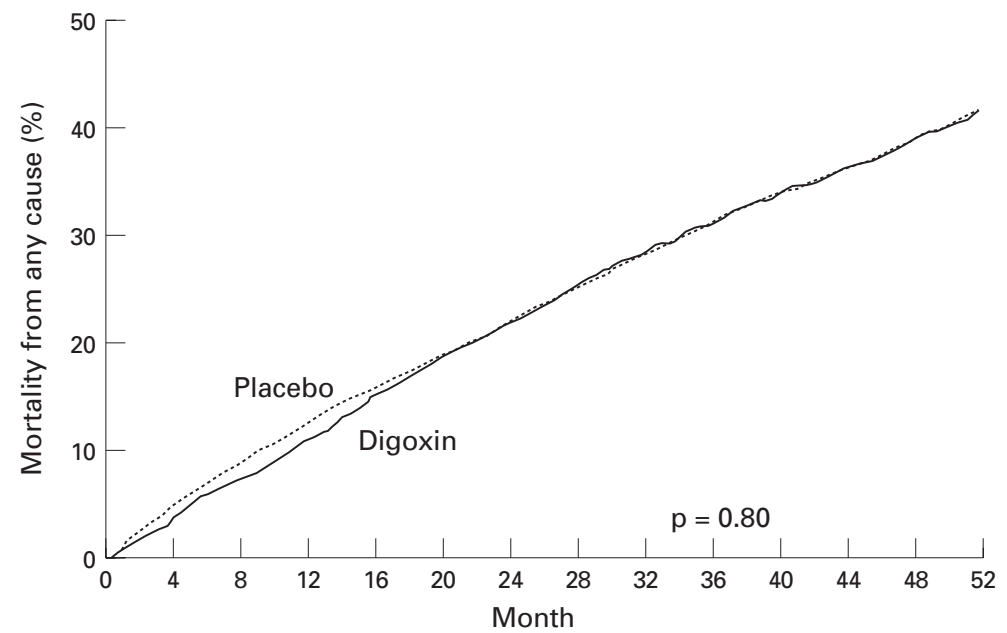

No. of patients at risk

$\begin{array}{llllllllllllll}\text { Placebo } 3403 & 3239 & 3105 & 2976 & 2868 & 2758 & 2652 & 2551 & 2205 & 1881 & 1506 & 1168 & 734 & 339\end{array}$ $\begin{array}{lllllllllllllll}\text { Digoxin } 3397 & 3269 & 3144 & 3019 & 2882 & 2759 & 2644 & 2531 & 2184 & 1840 & 1475 & 1158 & 737 & 335\end{array}$

Figure 1 All cause mortality in patients with moderate heart failure receiving background medication including ACE inhibition and diuretics. All cause mortality is similar in patients receiving digoxin and placebo. The number of patients at risk at each four month interval is shown below the figure. (Reproduced with permission from The Digitalis

Investigation Group. N Engl f Med 1997;336:525-33.)

Importantly, the increased intracellular cellular calcium concentrations in heart muscle have the potential to overload the sarcoplasmic reticulum and this may result in spontaneous release of calcium ions, which are arrhythmogenic. Calcium overload also increases myocardial energy consumption. For these reasons, digitalis glycosides may increase arrhythmias and mortality. ${ }^{4}$

A recent, large, placebo controlled trial, the DIG study, ${ }^{5}$ investigated the effects of digoxin on mortality in patients with predominantly moderate heart failure. It showed that all cause mortality was not affected by digoxin but was comparable to that in the placebo group (fig 1). The results suggest that digoxin had a beneficial effect in preventing progression of heart failure, as deaths from worsening heart failure were reduced significantly. On the other hand, a number of patients died prematurely because of arrhythmias. Whether the latter was related to raised digoxin concentrations has yet to be evaluated.

In conjunction with other controlled trials, the DIG trial shows that digoxin improves symptoms of patients with severe heart failure who are in sinus rhythm. As a result, the European guidelines on treatment of heart failure indicate the usefulness of digoxin in these patients. If patients improve to milder forms of heart failure, digitalis glycosides should be continued. Atrial fibrillation in heart failure patients is a clear indication for the use of digitalis glycosides.

DIURETICS

It is well recognised that diuretics are crucial for the symptomatic treatment of heart failure whenever fluid retention is present. In the more advanced stages of heart failure, alleviating fluid retention reduces preload and wall stress, and may have a beneficial effect on remodelling. On the other hand, diuretic treatment leads to neurohormonal activation, particularly of the renin-angiotensin system. This could precipitate remodelling. As diuretics apparently have a dual effect, it is uncertain what the overall outcome of their use will be, particularly in milder forms of heart failure.

Diuretic induced neurohormonal activation has been shown in a number of studies. In patients receiving diuretics and ACE inhibitors this activation is observed as increases in aldosterone, angiotensin II, and renin (fig 2), ${ }^{67}$ and, in some studies, as increases in noradrenaline. In patients receiving diuretics alone, the increase in renin activity is more pronounced than with combination treatment of diuretics plus ACE inhibitors. ${ }^{8}$

The effects of diuretics on left ventricular function have been studied in a three way parallel group trial. Patients were randomised to a combination of hydralazine plus isosorbide dinitrate, or diuretic monotherapy, or diuretics plus digoxin. In patients receiving diuretic monotherapy there was a consistent reduction in left ventricular ejection fraction that was not observed in the patients who received vasodilators.

The European guidelines on treatment of heart failure indicate that diuretics are indicated in virtually all forms of heart failure; the exception being milder forms in the absence of fluid retention (table 1). ${ }^{9}$ They should not be given as first line treatment, but rather after ACE inhibition has been instituted. The initial choice of diuretic drug lies with the physician and can be either a loop diuretic or a thiazide. However, the latter form of diuretic treatment is dependent on pre-existing renal function and may not be useful when the patient has renal dysfunction. In cases of more severe heart failure, it may be necessary to combine loop diuretics and thiazides to increase diure-
Figure 2 Stimulation of renin-angiotensin and plasma aldosterone in untreated patients with heart failure several weeks after initiation of diuretic treatment. Noradrenaline concentrations decrease, which coincides with clinical improvement. (Reproduced from Bayliss $\mathcal{F}$, Norell M, CanepaAnson R, et al. Br Heart $\mathcal{F}$ 1987;57:17-22, with permission of $B M 7$ Publishing Group.)
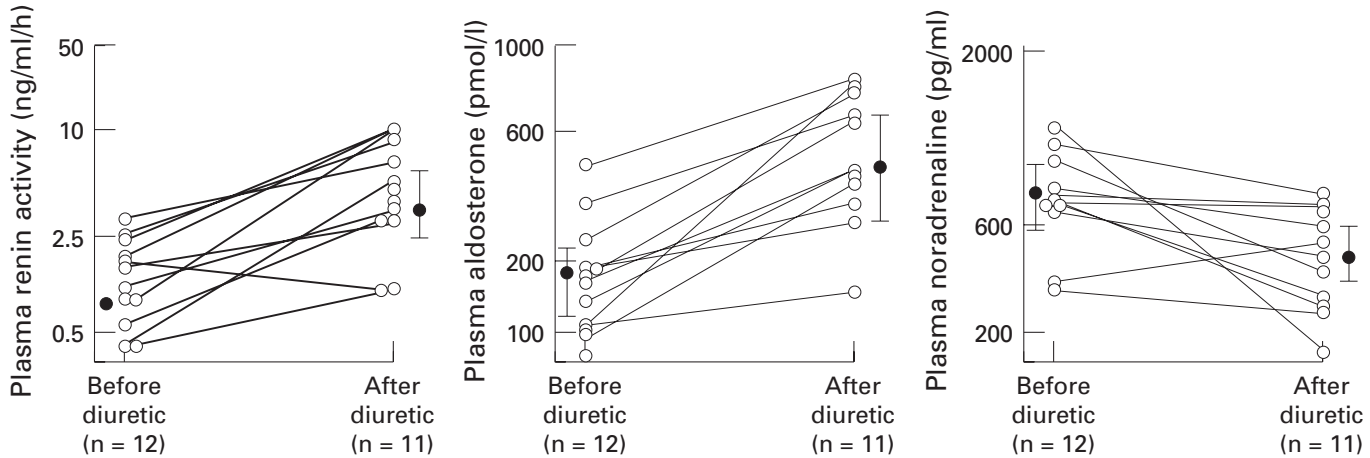
Table 1 Chronic heart failure: choice of pharmacological treatment

\begin{tabular}{|c|c|c|c|c|c|c|c|}
\hline & & $A C E$ inhibitors & Diuretics & $\begin{array}{l}\text { Potassium } \\
\text { sparing } \\
\text { diuretics }\end{array}$ & Cardiac glycosides & $\begin{array}{l}\text { Vasodilators } \\
\text { (hydralazinel } \\
\text { ISDN) }\end{array}$ & $\beta$ blockers \\
\hline Asymptomatic & $\begin{array}{l}\text { Left ventricular } \\
\text { dysfunction }\end{array}$ & $\begin{array}{l}\text { Indicated } \\
\text { in some }\end{array}$ & $\begin{array}{l}\text { Not indicated } \\
\text { (unless blood } \\
\text { pressure increased) }\end{array}$ & Not indicated & $\begin{array}{l}\text { Only with atrial } \\
\text { fibrillation }\end{array}$ & Not indicated & Post MI \\
\hline \multirow[t]{3}{*}{ Symptomatic } & NYHA II & & & & $\begin{array}{l}\text { When atrial } \\
\text { fibrillation is } \\
\text { present, or when } \\
\text { improved from } \\
\text { more severe HF } \\
\text { in sinus rhythm }\end{array}$ & & $\begin{array}{r}\text { Indicated (under } \\
\text { specialist care) }\end{array}$ \\
\hline & No fluid retention & Indicated & $\begin{array}{l}\text { Indicated } \\
\text { in some }\end{array}$ & Not indicated & & If ACE inhibitors & \\
\hline & Fluid retention & Indicated & Indicated & $\begin{array}{l}\text { Persisting } \\
\text { hypokalaemia }\end{array}$ & & $\begin{array}{l}\text { If ACE inhibitors } \\
\text { are not tolerated } \\
\text { or insufficient }\end{array}$ & \\
\hline Worsening/severe & NYHA III-IV & Indicated & $\begin{array}{l}\text { Indicated, } \\
\text { combinations } \\
\text { of diuretics }\end{array}$ & $\begin{array}{l}\text { Persisting } \\
\text { hypokalaemia; } \\
\text { spironolactone } \\
\text { for efficacy }\end{array}$ & Indicated & $\begin{array}{l}\text { If ACE inhibitors } \\
\text { are not tolerated } \\
\text { or insufficient }\end{array}$ & $\begin{array}{l}\text { Indicated (under } \\
\text { specialist care) }\end{array}$ \\
\hline End stage & Persisting NYHA IV & Indicated & $\begin{array}{l}\text { Indicated, } \\
\text { combinations } \\
\text { of diuretics }\end{array}$ & $\begin{array}{l}\text { Persisting } \\
\text { hypokalaemia; } \\
\text { spironolactone } \\
\text { for efficacy }\end{array}$ & Indicated & $\begin{array}{l}\text { If ACE inhibitors } \\
\text { are not tolerated } \\
\text { or insufficient }\end{array}$ & $\begin{array}{l}\text { Indicated (under } \\
\text { specialist care) }\end{array}$ \\
\hline
\end{tabular}

^Preliminary data from the DIG trial suggest that digoxin may also be indicated in NYHA II heart failure and sinus rhythm. $\mathrm{ACE}$, angiotensin converting enzyme inhibitors; HF, heart failure; ISDN, isosorbide dinitrate; MI, myocardial infarction.

Table 2 Aldosterone: its role in the pathophysiology of heart failure

Factors potentially involved in progressive $L V$ dysfunction and $\mathrm{CHF}$, arrhythmias, and myocardial ischaemia

\section{$\mathrm{Na}^{+} / \mathrm{H}_{2} \mathrm{O}$ retention}

$\mathrm{K}^{+}$loss

$\mathrm{Mg}^{2+}$ loss

Cardiovascular fibrosis

Reduction of cardiac catecholamine uptake

Endothelial dysfunction

Postangioplasty neointimal hyperplasia

Reduction HDL cholesterol

LV, left ventricular; CHF, congestive heart failure; HDL, high density lipoprotein.

sis. In severe cases, continuous intravenous administration, rather than intermittent administration of loop diuretics, is advocated.

SPIRONOLACTONE

Although the introduction of ACE inhibitors has reduced the need for potassium sparing diuretics, unless there is persisting hypokalaemia despite ACE inhibition, there may still be a place for spironolactone-an

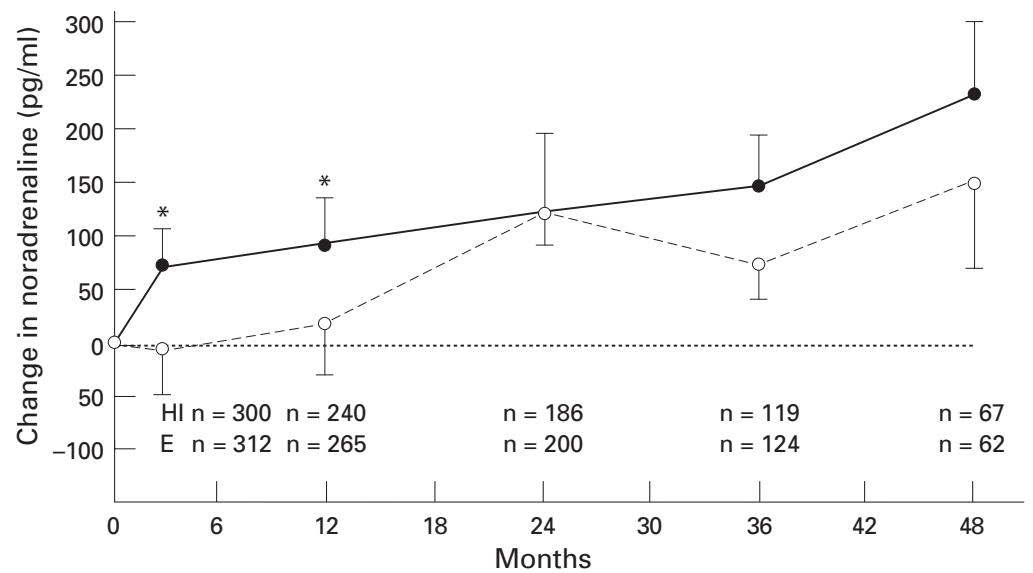

Figure 3 Change in serum noradrenaline concentrations following institution of hydralazine and isosorbide dinitrate (solid line) or enalapril (dashed line) in patients with mild to moderate heart failure in the V-HeFT II trial. The hydralazine, isorbide dinitrate combination results in an early significant increase in plasma noradrenaline that persists and increases over time. In contrast, there is an initial suppression, followed by an increas in noradrenaline with enalapril. ${ }^{\star} p<0.05$. (Reproduced with permission from Cohn $\mathfrak{F}$, Fohnson G, Ziesche S, et al. N Engl f Med 1991;325:303-10.) aldosterone receptor antagonist. In addition to potassium sparing and diuretic effects, spironolactone may have other properties that are important in the prevention of worsening of heart failure (table 2). It may inhibit cardiac fibrosis, which by itself could have protective effects on mortality, but the benefit may be amplified by additional properties such as an increase in cardiac potassium and magnesium concentrations, which may lead to fewer ventricular arrhythmias. A protective effect of spironolactone on mortality is currently being investigated in the RALES study, a large trial in moderate and severe heart failure. ${ }^{10}$

VASODILATORS

Exercise function measured as $\mathrm{PVO}_{2}$ is used in clinical trials as a clinical exponent of wellbeing. In the V-HeFT studies, patients treated with a combination of hydralazine and isosorbide dinitrate together with diuretics had a lower mortality than patients treated with diuretics alone. In V-HeFT II, however, the vasodilators had less effect on mortality than did enalapril. ${ }^{11}$ Thus, the combination of hydralazine and isosorbide dinitrate improves mortality compared with diuretics, but not compared with ACE inhibitors. Previous studies have indicated that vasodilators activate neurohormones. The V-HeFT II trial also showed an immediate increase in plasma noradrenaline concentrations with the institution of vasodilator treatment, which persisted over time (fig 3). With enalapril, no immediate increase in noradrenaline was seen until at least after 12 months of treatment. Thereafter noradrenaline concentrations also increased in patients treated with enalapril. This difference in neurohormonal activation during the first year may explain the difference in mortality. In line with the results of the V-HeFT trials, the European guidelines on treatment of heart failure indicate that the combination of hydralazine and dinitrates should be used in patients who cannot tolerate ACE inhibitors or, in more severe cases, together with ACE inhibitors (table 1). 

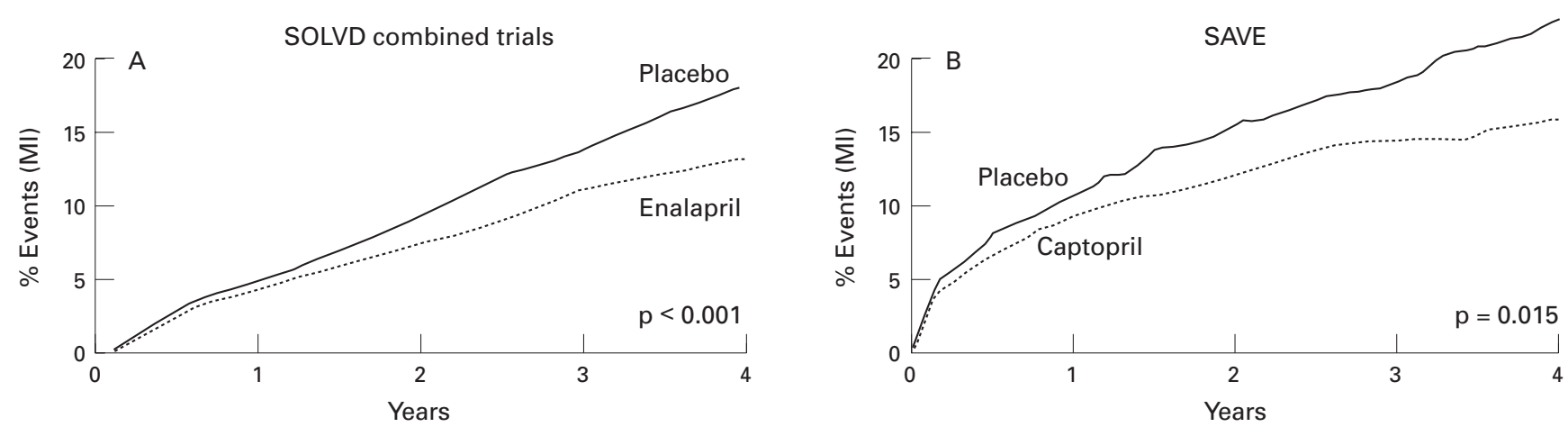

Figure 4 Cumulative incidence of myocardial infarction in the SOLVD combined trial database and the SAVE trial. (Adapted with permission from Rutherford FD, Pfeffer MA, Moye LA, et al. Circulation 1994;90:1731-8 and Yusuf S, Pepine CF, Garces C, et al. Lancet 1992;340:1173-8.)

\section{ACE INHIBITORS}

In the past decade, ACE inhibitors have become the cornerstone of treatment for heart failure. The guidelines on treatment of heart failure of the European Society of Cardiology show that ACE inhibitors are indicated in all phases of symptomatic heart failure and should be considered in patients with asymptomatic left ventricular dysfunction (ejection fraction $\leqslant 45 \%$ ) (table 1 ), particularly in patients with enlarged hearts. In patients with asymptomatic ischaemic left ventricular dysfunction ACE inhibitors protect against the development of heart failure, and in those with clinical heart failure there is an improvement in $50-80 \%$ of cases. ACE inhibitors reduce mortality to $16 \%$ in the first year in patients with moderate heart failure, and to $31 \%$ in those with severe heart failure. In postmyocardial infarction patients, ACE inhibitors reduce long term mortality to $19-27 \%$, depending on the presence of signs of heart failure during the acute and subacute phase of myocardial infarction.

The long term beneficial effects of ACE inhibitors are likely to be related to their positive effect on remodelling. They reduce left ventricular dilatation, and animal models have shown that they may reduce inappropriate left ventricular hypertrophy. Left ventricular end diastolic volume increases over time in patients given placebos, whereas this effect is diminished by ACE inhibitors. Importantly, ACE inhibitors have a positive effect on ischaemic outcomes as defined by the development of unstable angina and myocardial reinfarction (fig 4). ${ }^{12}$ Thus, 12 month morbidity resulting from ischaemic events is significantly reduced by ACE inhibitors. This has an important impact on mortality as it has been estimated that if a patient has an intercurrent myocardial infarction, the mortality risk increases fourfold with an accompanying increase in hospital admissions.

\section{ACE inhibitor treatment in heart failure: Utopia?}

ACE inhibition definitely has improved the potential to treat heart failure. However, is it enough? The answer clearly is "no" as there is still significant mortality. In the CONSENSUS trial in severe heart failure, the mortality after one year of patients taking ACE inhibitors was $36 \%,{ }^{12} 14$ and in the SOLVD treatment study of moderate heart failure the four year mortality rate of patients taking enalapril was $35 \% .{ }^{13}{ }^{15}$ In the AIRE study, a placebo controlled trial of ramipril in patients who, during the acute phase of myocardial infarction, had signs of heart failure, there was a significant reduction in overall mortality with ramipril at 15 months after the infarct ${ }^{1416}$; however, mortality remained at $17 \%$ in the treated group. In addition, although several trials have shown that ACE inhibitor treatment significantly reduces hospitalisation for cardiovascular reasons, in the SOLVD treatment study $57 \%$ of patients taking enalapril were hospitalised within a 41 month treatment period, and in the SOLVD prevention trial this figure was $41 \%$.

The side effects of ACE inhibitors are reportedly of less concern than for other forms of heart failure treatment but they may be severe enough to cause withdrawal from treatment. In severe heart failure, serum creatinine increases by $10-15 \%$, irrespective of baseline concentration. ${ }^{14}$ Trials have indicated that small reductions in blood pressure may occur; however, the clinical improvement with ACE inhibition is as good in patients with low baseline blood pressure or further reductions in blood pressure as in those who have a normal blood pressure at baseline or in whom blood pressure does not change.

Cough is a typical side effect of ACE inhibitor treatment, although excess cough may occur in only $2 \%$ of treated patients compared with placebo. This side effect is often worrisome enough to reduce the dosage of the drug to levels not proved to affect morbidity or mortality, or to cause withdrawal of the ACE inhibitor altogether.

What are the reasons for this inadequate response to ACE inhibition in heart failure? If angiotensin II, the effector peptide of the renin-angiotensin system, is to be sufficiently inhibited then either high dosages of short acting ACE inhibitors or relatively long acting ACE inhibitors are needed. Increments in ACE inhibitor dose augment the reduction in circulating angiotensin II. ${ }^{17}$ In clinical practice the dosages used are generally much lower than the target dosages that show benefit in large trials. Consequently, complete suppres- 
sion of angiotensin II production may fail over time. Moreover, increased plasma renin activity and subsequent angiotensin I accumulation occurs after ACE inhibition and this competes with the drug in binding with angiotensin converting enzyme causing an increase in angiotensin II formation. Alternatively, angiotensin I may stimulate angiotensin II production through other routes, possibly involving cardiac chymases bypassing the angiotensin converting enzyme. ${ }^{18}$ These factors may explain the insufficient suppression of circulating angiotensin II during long term ACE inhibitor treatment in left ventricular dysfunction and heart failure. ${ }^{19}$

Together, these theoretical and observational arguments support using high dosages of ACE inhibitors in left ventricular dysfunction and heart failure. Large trials, such as the ATLAS study, which are designed to compare the effect of high and low dose ACE inhibition on clinical symptoms and survival in heart failure, provide further insight into the question whether high dose ACE inhibition is indeed necessary in the treatment of heart failure.

\section{Prevention of worsening heart failure: future perspectives}

Most available heart failure treatment focuses on symptomatic treatment. Some forms of medication have a broader potential and may be useful in the prevention of progression and reduction of mortality. In this context, ACE inhibition has been the most important development of the past decade but it is unlikely to be sufficient as many mechanisms underlie worsening of heart failure, including neurohormonal activation, cardiac remodelling, cytokine activation, alterations in nitric oxide synthase expression, apoptosis, and myocardial ischaemia. ${ }^{20}$ The complexity of these mechanisms indicates that different forms of treatment modulating one or more of these mechanisms would also be useful in retarding or preventing the chain of events leading to progression. Examples of potentially useful drugs in this regard include angiotensin II receptor antagonists, spironolactone, and endothelin receptor antagonists, ${ }^{21}$ but there are insufficient data to confirm this. This is in contrast to extensive clinical experience with $\beta_{1}$ receptor antagonists, particularly with carvedilol, which has demonstrated value in heart failure.

\section{Conclusions}

The final goals of managing heart failure have not been attained. Mortality rates for patients with heart failure have been estimated at $36 \%$ at one year in severe heart failure ${ }^{14}$ and $35 \%$ at four years in moderate heart failure ${ }^{15}$ despite ACE inhibitor treatment.

Drugs used to treat heart failure are associated with side effects including renal dysfunction, electrolyte imbalance, and cough. In $15 \%$ of cases such side effects result in discon- tinuation of treatment. Moreover, ACE inhibitors fail to reduce mortality in asymptomatic patients with left ventricular dysfunction. One of the reasons for this lack of efficacy is the use of relatively low dosages that have not been proved to be effective. Low doses of ACE inhibitors are associated with a short duration of effect and this compromises efficacy. ACE inhibitors increase renin and angiotensin II activity, which may compete with angiotensin converting enzyme. There is also activation of alternative pathways of angiotensin production that results in a breakthrough of the effect of the ACE inhibitor. These factors complicate management.

It is unlikely that these problems will be solved in the short term because there is a complexity of mechanisms that exacerbate left ventricular function. For this reason a number of new categories of treatment are being developed.

1 Sigurdsson A, Swedberg K. The role of neurohormona activation in chronic heart failure and postmyocardia infarction. Am Heart f 1996;132:229-34.

2 Remme WJ. Inodilator therapy for heart failure - early, late, or not at all? Circulation 1993;87:IV-97-IV-107.

3 Remme WJ. Positive inotropic therapy-dead end or new horizon? f Cardiac Failure 1996;2(suppl 4):S267-76.

4 Remme WJ. Inotropic agents for heart failure: what if digoxin increases mortality? Br Heart $\mathcal{f}$ 1994;72(suppl): $92-9$.

5 The Digitalis Investigation Group. The effect of digoxin on mortality and morbidity in patients with heart failure. $N$ Engl f Med 1997;336:525-33.

6 Bayliss J, Norell M, Canepa-Anson R, et al. Untreated heart failure: clinical and neuroendocrine effects of introducing diuretics. Br Heart f 1987;57:17-22.

7 Broqvist M, Dahlström U, Karlberg BE, et al. Neuroendocrine response in acute heart failure and the influence of treatment. Eur Heart F 1989;10:1075-83.

8 Cleland JGF, Gillen G, Dargie HJ. The effects of frusemide and angiotensin-converting enzyme inhibitors and their combination on cardiac and renal haemodynamics in heart failure. Eur Heart F 1988;9:132-42.

9 The Task Force of the Working Group on Heart Failure of the European Society of Cardiology. Guidelines for the treatment of heart failure. Eur Heart $\mathcal{F}$ 1997; 18:736-53.

10 Pitt D. ACE inhibitor co-therapy in patients with heart failure: rationale for the randomized aldactone evaluation
study (RALES). Eur Heart $\mathcal{f} 1995 ; 16$ (suppl N):107-10.

11 Cohn JN, Johnson G, Ziesche S, et al. A comparison of enalapril with hydralazine-isosorbide dinitrate in the treatment of congestive heart failure. N Engl f Med 1991; 325:303-10

12 Rutherford JD, Pfeffer MA, Moye LA, et al. Effects of captopril in ischemic events after myocardial infarction. Results of the survival and ventricular enlargement trial. Circulation 1994;90:1731-8.

13 Yusuf S, Pepine CJ, Garces C, et al. Effect of enalapril in myocardial infarction and unstable angina in patient with low ejection fractions. Lancet 1992;340:1173-8

14 The CONSENSUS Trial Study Group. Effects of enalapril on mortality in severe congestive heart failure: results of the cooperative north Scandinavian enalapril survival the cooperative north Scandinavian enalapril survival study $1429-35$.

15 The SOLVD Investigators. Effect of enalapril on survival in patients with reduced left ventricular ejection fraction and congestive heart failure. $N$ Engl f Med 1991;325: 293-302.

16 The Acute Infarction Ramipril Efficacy (AIRE) Study Investigators. Effect of ramipril on mortality and morbidity of survivors of acute myocardial infarction with clinica evidence of heart failure. Lancet 1993;342:821-8.

17 Nussberger J, Fleck E, Bahrmann H, et al. Dose-related effects of ACE inhibition in man: quinapril in patients with moderate congestive heart failure. Eur Heart 7 1994,

15(suppl D): $113-22$.
18 Urata H, Nishimura H, Ganten D. Mechanisms of angiotensin II formation in humans. Eur Heart f 1995;16 (suppl N):79-85.

19 Sigurdsson A, Swedberg K, Ullman B. Effects of ramipril on the neurohormonal response to exercise in patients on the neurohormonal response to exercise in patients

20 Remme WJ. Prevention of worsening heart failure: future focus. Eur Heart f. [In press.]

21 Remme WJ. Neurohormonal modulation in heart failure ACE inhibition and beyond. Eur Heart $\mathcal{J}$ 1995;16 (suppl N):73-8 